\title{
Forecasting Tourism Demand with Composite Indicator Approach for Fiji
}

\author{
Ann-Ni Soh \\ Faculty of Economics and Business, Universiti Malaysia Sarawak \\ 94300 Kota Samarahan, Sarawak, Malaysia \\ Chin-Hong Puah (Corresponding author) \\ Faculty of Economics and Business, Universiti Malaysia Sarawak \\ 94300 Kota Samarahan, Sarawak, Malaysia \\ E-mail: chpuah@unimas.my \\ M. Affendy Arip \\ Faculty of Economics and Business, Universiti Malaysia Sarawak \\ 94300 Kota Samarahan, Sarawak, Malaysia
}

Received: August 20, 2019 Accepted: September 6, 2019 Published: September 23, 2019

doi:10.5296/ber.v9i4.15502

URL: https://doi.org/10.5296/ber.v9i4.15502

\begin{abstract}
This study attempts to scrutinize the fluctuations of the Fijian tourism market and forecast the early warning signals of tourism market vulnerability using the tourism composite indicator (TCI). The data employed on a monthly basis from 2000M01 to 2017M12 and the indicator construction steps were adopted from the ideology of the National Bureau of Economic Research (NBER). A parsimonious macroeconomic and non-economic fundamental determinant are included for the construction of TCI. Subsequently, the procedure then employed the seasonal adjustment using Census X-12, Christiano-Fitzgerald filtering approach, and Bry-Boschan dating algorithm. Empirical evidence highlighted the signalling attributes against Fijian tourism demand with an average lead time of 2.75 months and around 54 percent of directional accuracy rate, which is significant at 5 percent significance level. Thus, the non-parametric technique can forecast the tourism market outlook and the constructed TCI can provide information content from a macroeconomic perspective for
\end{abstract}


policymakers, tourism market players and investors.

Keywords: Tourism composite indicator, Early warning signal, Non-parametric approach, Tourism demand forecasting

\section{Introduction}

In line with the UNWTO World Tourism Barometer, a total of 1.4 billion international tourist arrivals, with 6 percent growth compared to the previous year, was recorded in 2018 . Furthermore, the World Tourism Organisation (UNWTO) also forecast an incremental growth of 3 to 4 percent of international tourist arrivals in conformity with the historical growth trend. Aside from the increasing importance of tourism for the global economy, there was growth for the regional economies in 2018. The Asia-Pacific region alone showed a remarkable growth of 6 percent in 2018 with 343 million international tourist arrivals (UNWTO, 2019). Moreover, tourism accounts for around one out of ten new job opportunities across the world. The outstanding performance of the global tourism industry worldwide affirms its position as one of the most powerful drivers of economic revenue and a catalyst for economic development. Hence, the tourism sector with its multiplier effects should achieve the real benefits for a country. Specifically, job creation, entrepreneurship and the involvement of local communities should leave no one behind in the revenue generated from the tourism sector despite the risk of economic leakage.

The general circumstance of the stability of oil price has been tentatively and highly linked to affordable air connectivity and stimulates the diversification of source markets. Strong outbound travel from emerging markets due to stable oil price can improve tourism growth in most destinations. Apart from the fluctuations of oil price, trade tensions will consequently inhibit investors and travellers from visiting a country. These global challenges for tourism also affect Pacific islands like Fiji.

According to the World Travel and Tourism Council (WTTC), international tourist arrivals and tourism receipts progressively show a positive trend over the past few decades despite political instability and other global crises. The international tourism receipts increase from USD 291 million to USD 1,188 million for 2000 and 2017 respectively. Concurrently, tourism arrivals have also shown a significant growth from 294 thousand travellers in 2000 up to approximately 796 travellers in 2017 for Fiji. Fiji is one of the small developing island countries and one of the tourism-dependent countries, recording 40.3 percent of tourism contribution to GDP. Thus, it is crucial to develop research to ensure the tourism development of Fiji can be managed in a sustainable manner by uncovering and addressing the underlying issues.

The tourism sector remains one of the largest contributors to the Fijian economy and the primary economic driver, supported by other industries for income generation such as agriculture, sugar and garment. However, there are a few challenges that need to be tackled cautiously to ensure that appropriate policy implications can be recommended for the further development of the Fijian tourism sector. The challenges of the Fijian tourism cycle are threefold: political turmoil that discourages collaboration with other Pacific countries and 
causes the devaluation of Fijian currency, high economic leakage which restrains the expansion of local communities, and high dependence on the Western market, which contributes to the inequality of market segment distribution. This situation has aroused our interest in forecasting the dynamic changes of the Fijian tourism cycle to ensure that national growth is sustainable despite its heavy reliance on tourism.

Previously, the vast amount of research on tourism demand modelling and forecasting has focused on its own symbolic contributions. Apart from the widespread qualitative research, a quantitative approach, i.e., the Delphi method, involved a structured communication technique utilised by Bosun and Modrak (2014). Quantitative methods in forecasting tourist arrivals can be generally categorised into causal methods and non-causal methods. Non-causal time series methods are popularised as one of the forecasting tools due to their accuracy. Saayman and Botha (2015) adopted the Seasonal Autoregressive Integrated Moving Average (SARIMA) model to forecast tourist arrivals that exhibit seasonality. Furthermore, Lin et al. (2015) and Puah et al. (2018a) employed an econometric approach and Autoregressive Distributed Lag (ARDL) approach, respectively, to predict China outbound tourism; China is regarded as the largest outbound tourism market that contributes significantly to the global tourism industry. Puah et al. (2018b) also employed the Autoregressive Distributed Lag (ARDL) approach that validated the tourism-led-growth hypothesis. From the regional economies point of view, Assaf et al. (2018) proposed the Bayesian global vector autoregressive (BGVAR) model in demonstrating the spill-over regional effect of tourism demand. Moreover, Soh et al. (2019) investigated the possible leading indicators in modelling the tourism demand using Markov regime-switching model. Despite the advancement of internet usage, Li et al. (2017) adopted the composite search index to be included in the generalized dynamic factor model to forecast the Chinese tourism demand.

Thus far, few have explored the indicator-based approach in the tourism context even though it has been popularized among other field of studies, especially from the business context where business cycle indicators are generalized to be employed as a useful forecasting tool. The movements of the economic cycle have been successfully monitored by using the composite indicator approach in constructing the business cycle indicator for different countries. Research done by Abu Mansor et al. (2015), Wong et al. (2016), Bilan et al. (2017), and Venter (2017) had successfully replicated the economic cyclical behaviour using the leading components and the constructed indicators as a short-term forecasting tool. Economic risk monitoring can be achieved using the constructed indicators, and the insights regarding movement of the economy can be portrayed clearly. Regarding the noteworthiness of the leading indicator approach, Puah et al. (2016) further explored it to forecast property market dynamics. Kocmanaova et al. (2017) employed a composite indicator to assess the measurement of corporate sustainability while Chong et al. (2018) constructed an oil price indicator to forecast the movement of global oil prices with an average lead time of 3.6 months. Thus far, Arip et al. (2019) utilised the non-parametric indicator approach to gauge the financial vulnerability for Malaysia and it managed to trace the episodes successfully. Hence, a similar approach can be further extended to the tourism field to find an early 
warning indicator for market dynamics.

Most of the small developing island-states including Fiji depend on the tourism sector in generating revenue. Tourism makes a significant contribution to GDP and employment opportunities. For the purpose of risk management and effective planning, tourism-related stakeholders are demanding valuable information to ensure strategic growth. The principal objective of this research is to construct a tourism composite indicator (TCI) and provide a chronology reference of monthly tourism cycles including the assessment of robustness of TCI. The constructed TCI with its empirical evidence can provide insights for the Fijian tourism market. Furthermore, the current research aims to anticipate the dynamic changes of the Fijian tourism cycle by embedding a non-parametric approach with dating procedures.

\section{Methodology}

Since the seminal papers of Arthur Burns and Wesley Mitchell, published in 1938 and 1946, both academicians and policymakers have shown increasing interest in the prominent role of leading indicators. Burns and Mitchell (1946) extended the classical business cycle analysis to generate the leading indicators. In general, it is an exercise in "measurement without theory" accompanied by some underlying theory that can clarify the relationship among the selected series. The conceptual framework for the present research is adapted from the ideology of National Bureau of Economic Research (NBER) in capturing the movement of the cycles. The Conference Board (2000) took over the responsibility of managing and publishing reports in the late 1960s. There are few exceptions for the time series; it is expected to survive as one of the component series even though no single time series can fully qualify as an ideal cyclical indicator. According to The Conference Board (2000), there are six considerations in selecting the appropriate component series: the concern of conformity, consistent timing, economic significance, statistical adequacy, smoothness, and being published in a reasonably prompt schedule.

A benchmark that can measure the tourism performance of Fiji needs to be established for the tourism early warning indicator. A comprehensive body of literature has suggested indicatory signs of the number of international tourist arrivals to depict the tourism growth. Moreover, Valadkhani and O'Mahony (2018) emphasized the role of international tourist arrivals (TA) as the global composite barometer for the inbound tourism market. Hence, TA is chosen as the benchmark reference series for the construction of TCI to illustrate Fijian tourism cycle fluctuations. Next, a total of five component variables were chosen as the component series: the Shanghai Stock Exchange Composite Index (SSEC), which denotes the financial performance of Chinese outbound tourism market; crude oil price (BRENT) which is a proxy for production costs and mainly transportation costs; political stability index (PSI), which presents the absence of terrorism or violence; visitor exports (VE), which denotes the arrivals of potential travellers; and foreign direct investment (FDI), which expresses the amount of investment flow into the Fijian nation.

After the determination of the component series and reference series, the credible guidelines published in The Conference Board (2000) are followed accordingly to construct the TCI. There are five demarcation procedures to construct the tourism composite indicator (TCI). 
First, compute month-to-month changes $\left(y_{i, t}\right)$ for respective component $\left(X_{i, t}\right)$, where $i=1, \ldots \ldots, n$. Simple arithmetic differences are computed as $y_{i, t}=X_{i, t}-X_{i, t-1}$. An alternative condition of symmetric changes can be calculated as $y_{i, t}=200 *\left(X_{i, t}-X_{i, t-1}\right) /\left(X_{i, t}+X_{i, t-1}\right)$. Second, multiply each of them by standardization factor of the component $\left(k_{i}\right)$ to adjust the month-to-month changes as $Z_{i, t}=\left(k_{i}\right) *\left(y_{i, t}\right)$. Third, the adjusted month-to-month changes are summed up following the step of $S_{t}=$ $\sum_{i=1}^{n} Z_{i, t}$. Fourth, we apply the symmetric percent change formula to compute the index in preliminary levels. The initial value of the index for first month is denoted as $I_{1}=100$ and the subsequent month will be interpreted as $I_{2}=100 *\left(200+S_{2}\right) /\left(200-S_{2}\right)$. The initiate index value for the subsequent month will be calculated as $I_{3}=I_{2} *\left(200+S_{3}\right) /\left(200-S_{3}\right)$. Fifth, we rebase the preliminary index of TCI into the base year. The preliminary indexes computed in the fourth step are multiplied by 100 and follow by the division of the preliminary levels mean $\mathrm{n}$ for the base year.

After the construction of TCI, we proceeded to the seasonal adjustment using Census X-12 proposed by Moore and Zarnowitz (1986). Seasonal adjustment is a statistical method used to eliminate seasonal patterns of the time series and is usually performed for trend or cyclical analysis. Next, the cyclical movements of the constructed TCI and TA cycle are then established using the filtering approach for trend extraction, introduced by Christiano and Fitzgerald (2003). Furthermore, the Bry-Boschan (BB) dating algorithm from the adaptation of NBER is used to determine the cyclical turning points for both cycles. In this case, the cyclical turning points can be outlined by economic phases, which are contraction and expansion phases. As mentioned earlier for the robustness test, directional accuracy and binomial tests are employed for the current study to determine the accuracy rate of the constructed TCI in anticipating the directional changes of the Fijian tourism cycle. Greer (2003) stated that the forecasting model has a directional accuracy rate higher than 50 percent and the binomial test significant at a 5 percent significance level, proving that the forecasting statistically outperforms speculation. The estimation results will be discussed in the following section.

This study gathered promptly updated data from various trustworthy sources to ensure the persistency performance on the constructed TCI. The sources were the CEIC Database, World Travel and Tourism Council (WTTC), and U.S. Energy Information Administration (EIA). The data employed in the current research were collected from 2000 until 2017. The data are then interpolated with Chow and Lin's (1971) approach to get a higher frequency of monthly data.

\section{Empirical Findings and Discussions}

Having discussed the implementation of the indicator construction technique and the growth cycle approach, the cyclical movements of TCI and TA are established accordingly. In line with the selection criteria listed by The Conference Board (2000), the selected component series with leading properties include SSEC, BRENT, PSI, VE, and FDI while the reference series is TA. The correlation analysis is then conducted to affirm the relationship between both series. The analysis findings are illustrated in Table 1. 


\section{Mll Macrothink}

Business and Economic Research

ISSN 2162-4860

2019, Vol. 9, No. 4

From the estimation results shown, BRENT, FDI and VE are classified as a suitable component series to be aggregated into the composite form, as the correlation with TA is approximately more than the value 0.55 . The conformity of SSEC to TA is slightly lower as compared to the other variables. Addressing one of the challenges of Fiji, the diversification of source markets is encouraged; e.g., to develop the Chinese market or other Asian markets as comparatively large outbound tourism markets. Therefore, SSEC denotes that the stock market performance of China possesses the leading characteristics needed for the Fiji tourism market. Moreover, China is the largest investor in Fiji, having contributed around 43 percent of total foreign investment in Fiji. Thus, the influence of the China market is a potentially significant factor in the Fijian tourism cycle. Although the PSI and TA do not exhibit strong relationship results from the correlation analysis, they are included as one of the component series. This is due to the role of PSI as a sentimental variable that can reflect national security, which is a crucial factor affecting the decision-making of tourists regarding whether to visit or not.

Table 1. Correlation Analysis Results

\begin{tabular}{|l|l|l|l|l|l|l|}
\hline & LTA & LBRENT & LFDI & LPSI & LSSEC & LVE \\
\hline LTA & 1.00 & & & & & \\
\hline LBRENT & 0.65 & 1.00 & & & & \\
\hline LFDI & 0.82 & 0.77 & 1.00 & & & \\
\hline LPSI & -0.01 & -0.53 & -0.29 & 1.00 & & \\
\hline LSSEC & 0.48 & 0.40 & 0.43 & -0.12 & 1.00 & \\
\hline LVE & 0.96 & 0.67 & 0.78 & -0.05 & 0.45 & 1.00 \\
\hline
\end{tabular}

As seen in Figure 1, the constructed TCI has a prominent role in leading the TA cycle, which is consistently attributed to the signalling effect on TA. Moreover, the major transitions of TCI from one turning point to another signal the shift towards TA. As a result, the empirical evidence recommends that the constructed TCI can trace the general movement of the Fijian tourism industry precisely in a well-timed manner. Several slumps occurred for the Fijian tourism market due to several crises that happened worldwide or within the nation itself. Several macroeconomic major events happened chronologically that influenced the Fijian tourism industry: The dot-com bubble burst and Fiji coup in 2000, global oil price hikes in 2005, the Fijian military coup in 2006, the repealing of the Constitution in 2008, the sub-prime mortgage crisis of 2008, and suspension from the Commonwealth in 2014. These major events have caused major fluctuations of the Fijian tourism cycle. 


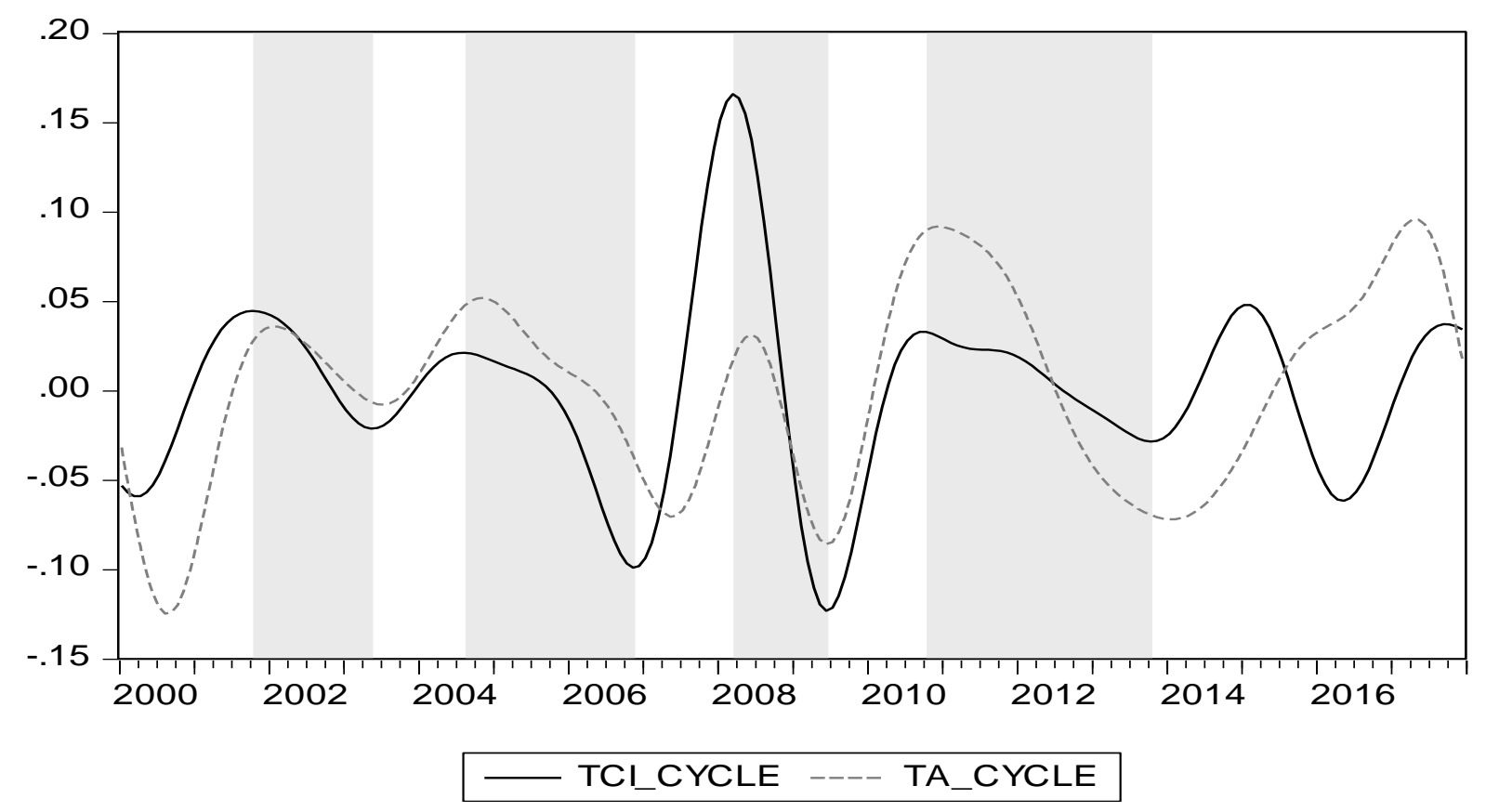

Figure 1. Cyclical Movements of TCI versus TA, 2000M01-2017M12

Table 2 unveils the turning point analysis results of the constructed TCI and the reference cycle TA from the BB dating algorithm. A total of four cycles have been traced by the BB test: Four peaks and four troughs from 2000 to 2017. A monthly chronology reference also has been established and the empirical evidence shows that the sequence of events is consistent with the Fijian trends for the past two decades. Comprehensively, the constructed TCI illustrates a short-term lead time for the Fijian tourism market, which accounted for an average of 2.75 months. This shows that the constructed TCI possesses the ability to predict the tourism market roadmap for Fiji. This can be greatly helpful for the government in deciding precautionary steps or remedial measures for crises. Thus far, the prominent lead time and the reliability in forecasting the movements of the Fijian tourism cycle is relatively useful due to the selected variables that are published in a prompt time schedule.

Table 2. Turning Points Analysis Results of TCI and TA

\begin{tabular}{|c|c|c|c|c|}
\hline Cycle Condition & TCI & TA & Number of Early Signal (s) & Major Events \\
\hline Peak & $2001 \mathrm{M} 10$ & $2002 \mathrm{M} 01$ & 3 & \multirow{2}{*}{$\begin{array}{ll}\text { - } & \text { Fiji coup } \\
\text { - } & \text { Dotcom bubble } \\
\end{array}$} \\
\hline Trough & 2003M05 & 2003M07 & 2 & \\
\hline Peak & 2004M08 & 2004M11 & 3 & \multirow{2}{*}{$\begin{array}{ll}\text { - } & \text { Global oil price hikes } \\
\text { - } & \text { Fijian political crisis } \\
\end{array}$} \\
\hline Trough & 2006M11 & 2007M05 & 6 & \\
\hline Peak & $2008 \mathrm{M} 03$ & $2008 \mathrm{M} 06$ & 3 & \multirow{2}{*}{$\begin{array}{ll}\text { - } & \text { Sub-prime mortgage crisis } \\
\text { - } & \text { Constitution repealed } \\
\end{array}$} \\
\hline Trough & 2009M06 & 2009M06 & 0 & \\
\hline Peak & $2010 \mathrm{M} 10$ & $2010 \mathrm{M} 12$ & 2 & \multirow{2}{*}{$\begin{array}{ll}\text { - } & \text { Suspension from } \\
\text { Commonwealth }\end{array}$} \\
\hline Trough & $2013 \mathrm{M} 10$ & $2014 \mathrm{M} 01$ & 3 & \\
\hline & & Average & 2.75 months & \\
\hline
\end{tabular}




\section{MlMacrothink}

Business and Economic Research

ISSN 2162-4860

2019, Vol. 9, No. 4

The final stage of the empirical test that identifies the directional accuracy changes of the constructed TCI is demonstrated in Table 3. The rejection of null hypothesis indicates that the probability of the constructed TCI can predict the direction of change correctly (Greer, 2003). The tabulated results show that the constructed TCI can predict Fijian major tourism cycle turning points up to around 54 percent and is statistically significant at 5 percent. Thus, the null hypothesis is rejected, and it is statistically proven that the constructed TCI is more dependable than speculation or mere chance. It is once again suggested that the constructed TCI has a promising predictive power for Fijian tourism fluctuation phases and provides reliable early warning signals for Fijian tourism market dynamics and vulnerability.

Table 3. Analysis Results of Directional Accuracy and Binomial Testing

\begin{tabular}{|c|c|c|}
\hline \multirow{2}{*}{ Lag (Month) } & \multicolumn{2}{|c|}{ TCI } \\
\cline { 2 - 3 } & Directional Accuracy (\%) & P-value (Binomial) \\
\hline Lag 1 & $53.95 \%$ & 0.028 \\
\hline Lag 2 & $53.74 \%$ & 0.030 \\
\hline Lag 3 & $53.52 \%$ & 0.032 \\
\hline Lag 4 & $53.30 \%$ & 0.035 \\
\hline Lag 5 & $53.08 \%$ & 0.037 \\
\hline Lag 6 & $52.86 \%$ & 0.039 \\
\hline
\end{tabular}

\section{Conclusion}

To sum up, considering the principal objectives in constructing a tourism composite indicator (TCI) for the Fijian tourism market vulnerability, the empirical findings prove that the ideology of the NBER can be applied in the tourism context. Despite the remarkable growth of the Fijian tourism sector, it is still affected by external shocks such as political crisis, global financial crisis, and the suspension from the Commonwealth. These significantly affected Fiji's trade-free agreements and banned travel from New Zealand. As the key exchange earners for the country, it is crucial that the policymakers ensure the tourism sector can be developed in a sustainable manner. The variables included in the component series can help them do this. The forecasting tool can provide early insights for tourism-related stakeholders, policymakers, and local communities in terms of risk management. Considering the important role of Fijian tourism and the limited research using the indicator approach, this study has taken the initiative to develop the TCI; it is applicable to other countries as well.

However, there are limitations for the study. Access to the original high-frequency data is certainly an inevitable limitation. The out-of-sample forecasting can be applied in further study as a comparison to the actual outcomes and this can create added value.

\section{Policy Recommendation}

There are several policy implications that can be recommended to minimize crisis impacts on the economy, especially for tourism. The policies inspired by the current research aim to ensure the continuous growth of the Fijian tourism market. Considering oil vulnerabilities, 
affordable oil pricing is incredibly important for the world economy, especially for the tourism sector. The government can choose to integrate a range of risk factors that embrace the oil price shocks during the development of marketing strategies. Furthermore, public-private partnerships are extremely important in financing and operating the tourism projects in Fiji. Funding allocations should especially focus on local entrepreneurs to prevent high economic leakage and thus improve economic prosperity. Additionally, policy intervention can be also applicable towards the external forces from China investors and travelers to diversify the western source market. The constructed TCI has proven that SSEC can provide early insights for Fijian tourism development. Producing a conducive business environment is crucial to attract more leisure or business travelers. In summation, crisis management and business continuity are important criteria for Fiji to sustain its tourism growth as a primary driver of revenue generation.

\section{References}

Abu Mansor, S., Liew, V. K. S., Puah, C. H., \& Wong, S. S. L. (2015). An early warning indicator of economic vulnerability constructing for Malaysian economy. Economic Annals-XXI, 3-4(1), 37-41.

Arip, M. A., Kuek, T. H., \& Puah, C. H. (2019). Forecasting financial vulnerability in Malaysia: A non-parametric indicator approach. Asian Journal of Business Research, 9(2), 113-120. https://doi.org/10.14707/ajbr.190063

Assaf, A. G., Li, G. Song, H., \& Tsionas, M. G. (2019). Modeling and forecasting regional tourism demand using the Bayesian global vector autoregressive (BGVAR) model. Journal of Travel Research, 58(3), 383-397. https://doi.org/10.1177/0047287518759226

Bilan, Y., Gavurova, B., Stanislaw, G., \& Tkacova, A. (2017). The composite coincident indicator for business cycles. Acta Polytechnica Hungarica, 14(7), 71-90.

https://doi.org/10.12700/APH.14.7.2017.7.5

Bosun, P., \& Modrak, V. (2014). Using the Delphi method in forecasting tourism activity. International Letters of Social and Humanistic Sciences, 25, 66-72.

https://doi.org/10.18052/www.scipress.com/ILSHS.25.66

Burns, A. F., \& Mitchell, W. C. (1946). Measuring business cycles. New York, NY: National Bureau of Economic Research.

Chow, G. C., \& Lin, A. (1971). Best linear unbiased interpolation, distribution, and extrapolation of time series by related series. The Review of Economics and Statistics, 53(4), 372-375. https://doi.org/10.2307/1928739

Christiano, L. J., \& Fitzgerald, T. J. (2003). The band pass filer. International Economic Review, 44(2), 435-465. https://doi.org/10.1111/1468-2354.t01-1-00076

Greer, M. (2003). Directional accuracy tests of long-term interest rate forecasts. International Journal of Forecasting, 19, 291-298. https://doi.org/10.1016/S0169-2070(01)00141-8

Li, X., Pan, B., Law, R., \& Huang, X. (2017). Forecasting tourism demand with composite 
search index. Tourism Management, 59, 57-66.https://doi.org/10.1016/j.tourman.2016.07.005

Lin, V. S., Liu, A., \& Song, H. (2015). Modeling and forecasting Chinese outbound tourism: An econometric approach. Journal of Travel and Tourism Marketing, 32(1-2), 34-49. https://doi.org/10.1080/10548408.2014.986011

Moore, G. H., \& Zarnowitz, V. (1986). The development and role of the National Bureau of Economic Research's business cycle chronologies. In R. J. Gordon (Ed.), The American Business Cycle: Continuity and Change (pp. 735-780). University of Chicago Press.

Puah, C. H., Huan, S. H., \& Thien, F. T. (2018a). Determinants of Chinese demand of tourism in Malaysia. Business and Economic Horizons, 14(3), 501-512.

https://doi.org/10.15208/beh.2018.36

Puah, C. H., Jong, M. C., Ayob, M., \& Ismail, S. (2018b). The impact of tourism on the local economy in Malaysia. International Journal of Business and Management, 13(12), 151-157. https://doi.org/10.5539/ijbm.v13n12p151

Puah, C. H., Kuek, T. H., Arip, M. A., \& Wong, S. S. L. (2016). Forecasting property market dynamics: Insights from the property cycle indicator. Information, 19(6B), 2225-2232.

Saayman, A., \& Botha, I. (2017). Non-linear models for tourism demand forecasting. Tourism Economics, 23(3), 594-613. https://doi.org/10.5367/te.2015.0532

Soh, A. N., Puah, C. H., Arip, M. A., \& Kuek, T. H. (2019, in press). Oil price and tourism cycle: A Markov regime-switching model. International Journal of Energy Economics and Policy.

The Conference Board. (2000). Business cycle indicators handbook. New York, NY: The Conference Board.

UNWTO. (2019). World Tourism Organization: International Tourist Arrivals Reach 1.4 billion Two Years Ahead of Forecast. [Online] Available:

http://www2.unwto.org/press-release/2019-01-21/international-tourist-arrivals-reach-14-billio n-two-years-ahead-forecasts

Valadkhani, A., \& O'Mahony, B. (2018). Identifying structural changes and regime switching in growing and declining inbound tourism markets in Australia. Current Issues in Tourism, 21(3), 277-300. http://dx.doi.org/10.1080/13683500.2015.1072504

Venter, J. C. (2017). Obtaining clear and timely business cycle turning point signals with a composite leading business cycle indicator. Studies in Economics and Econometrics, 41(3), 39-59.

Wong, S. S. L., Puah, C. H., Abu Mansor, S., \& Liew, V. K. S. (2016). Measuring business cycle fluctuations: an alternative precursor to economic crises. Economic Computation and Economic Cybernetics Studies and Research, 50(4), 235-248. 


\section{Copyright Disclaimer}

Copyright for this article is retained by the author(s), with first publication rights granted to the journal.

This is an open-access article distributed under the terms and conditions of the Creative Commons Attribution license (http://creativecommons.org/licenses/by/3.0/). 